\title{
Cellular Bases of Brain Energy Metabolism and Their Relevance to Functional Brain Imaging: Evidence for a Prominent Role of Astrocytes
}

\section{Survey of Brain Energy Metabolism at the Organ and Regional Levels}

\section{Organ Level}

Fundamental observations on brain energy metabolism at the organ level culminated over 40 years ago, in particular through the pioneering work of Schmidt and Kety (1948). By determining arteriovenous (A-V) differences of a number of metabolic substrates the view emerged that, except under certain nonphysiological conditions, glucose is the obligatory energy substrate for the brain (Edvinsson et al., 1993). Glucose utilization by the brain is $31 \mu \mathrm{mol} / 100 \mathrm{gm} / \mathrm{min}$, while oxygen consumption is $160 \mu \mathrm{mol} / 100 \mathrm{gm} / \mathrm{min}$; since $\mathrm{CO}_{2}$ production is almost identical, the respiratory quotient (RQ) of the brain is nearly 1 , indicating that carbohydrates are the substrates for oxidative metabolism (Sokoloff, 1960). With a global blood flow of $57 \mathrm{ml} / 100 \mathrm{gm} / \mathrm{min}$, the brain extracts approximately $50 \%$ of oxygen and $10 \%$ of glucose from the arterial blood. Given a theoretical stoichiometry of $6 \mu \mathrm{mol}$ of oxygen consumed for each $\mu \mathrm{mol}$ of glucose, the expected brain glucose utilization should in theory be $26.6 \mu \mathrm{mol} / 100$ $\mathrm{gm} / \mathrm{min}$ rather than the measured $31 \mu \mathrm{mol} / 100 \mathrm{gm} / \mathrm{min}$; thus, an excess of $4.4 \mu \mathrm{mol} / 100 \mathrm{gm} / \mathrm{min}$ of glucose follows other metabolic fates. These include the production of lactate and pyruvate which do not necessarily enter the tricarboxylic acid cycle, but rather, can be released into the circulation Glucose can also be incorporated into lipids, proteins, and glycogen, and it is the precursor of certain neurotransmitters such as GABA, glutamate, and acetylcholine (Sokoloff, 1989; Edvinsson et al., 1993).

It should also be noted that a limited proportion of oxygen is actually utilized for purposes other that direct energy generation. Neural cells contain oxydases and hydroxylases, which are key regulatory enzymes in the metabolic pathways of a number of neuroactive molecules. Examples of such oxygen-requiring enzymes are cyclooxygenases and lipoxygenases involved in the synthesis of eicosanoids from arachidonic acid, tyrosine and tryptophan hydroxylases, dopamine- $\beta$-hydroxylase, and monoamine oxidase, which are all enzymes that regulate the metabolism of monoamine neurotransmitters (Keevil and Mason, 1978). The recently discovered NO synthase pathway also consumes oxygen (Klatt et al., 1993).

Certain metabolic intermediates, under particular conditions, can substitute for glucose as alternative substrates for brain energy metabolism (Sokoloff, 1989). Thus starvation, diabetes, or breast-feeding in neonates all lead to increased plasma levels of the ketone bodies acetoacetate and D-3-hydroxybutyrate, which can be used by the brain as metabolic substrates (Sokoloff, 1989). Mannose, which is not normally present in the blood and cannot therefore be considered a physiological substrate, can sustain normal brain function in the absence of glucose. Lactate and pyruvate can sustain synaptic activity in vitro (Mcllwain and Bachelard, 1985; Schurr et al., 1988). Because of their limited permeability across the blood-brain barrier, they cannot adequately substitute for plasma glucose to maintain brain function (Pardridge and Old-
Pierre J. Magistretti and Luc Pellerin

Institut de Physiologie, Faculté de Médecine, Université de Lausanne, CH-1005 Lausanne, Switzerland

endorf, 1977). However, if formed inside the brain parenchyma, they are useful metabolic substrates for neural cells (Mcllwain, 1953; Ide et al., 1969; Teller et al., 1977). Net release of lactate and pyruvate (negative $\mathrm{A}-\mathrm{V}$ difference) is occasionally measured in normal individuals, and more frequently in aged subjects or during convulsions (Kety, 1957; Cohen et al., 1967; Folbergrova, 1974). Since steady-state arteriovenous (A-V) differences provide indirect evidence that a substance can be either used as a substrate by the brain (positive A-V difference) or produced by the brain (negative $A-V$ difference) these observations indicate a variable degree of glycolytic glucose processing by the brain (Fig. 1).

\section{Regional Level}

Studies at the organ level, while revealing the global substrate requirements for the brain and their stoichiometry, failed to provide the appropriate level of resolution to appreciate two major features of brain energy metabolism: (1) its regional heterogeneity, and (2) its tight relationship with the functional activation of specific pathways. A major technical advance that brought the regional resolution to studies of brain energy metabolism and that laid the ground for visualization of neural activity, is the autoradiographic 2-deoxyglucose method (2DG) developed by Sokoloff and colleagues. With this technique, local rates of glucose utilization (LCMRglu) can be determined with a spatial resolution of approximately 50-100 $\mu \mathrm{m}$ (Sokoloff et al., 1977; Sokoloff, 1981).

Using the 2-DG autoradiographic technique, LCRMglu have been determined in virtually all structurally and functionally defined brain regions during various physiological and pathological states. Activation of pathways subserving specific modalities, such as visual, auditory, olfactory, or somatosensory stimulations as well as motor activity has also been revealed in the pertinent brain structures by the 2-DG technique (Sharp et al., 1975; Kennedy et al., 1976; Wolf et al., 1983; Melzer et al., 1985; Ginsberg et al., 1987). A consistent finding has been that the increase in 2-DG uptake linked to functional activation occurs in the neuropil, that is, in regions that are enriched in axon terminals, dendrites, and synapses ensheathed by astrocytic processes, and not where neuronal perikarya are located (Kadekaro et al., 1985; Sokoloff, 1991). Given the complex intertwining of neural processes in the nervous system, this observation is particularly apparent in those circuits in which a clear-cut polarization of neural process exists (Roland, 1993). Thus, a striking example was provided by a study of Sokoloff and colleagues showing that when the sciatic nerve of anesthetized rats is stimulated, a frequency-dependent increase in 2-DG uptake occurs in the dorsal horn of the spinal cord (where afferent axon terminals make synaptic contacts with second order neurons) but not in the dorsal root ganglion, where the cell body of the sensory neurons is localized (Kadekaro et al., 1985). As another example, increases in glucose utilization in the well-laminated monkey primary visual cortex elicited by appropriate visual stimuli, are most pronounced in layer IV, which is poor in perikarya but 


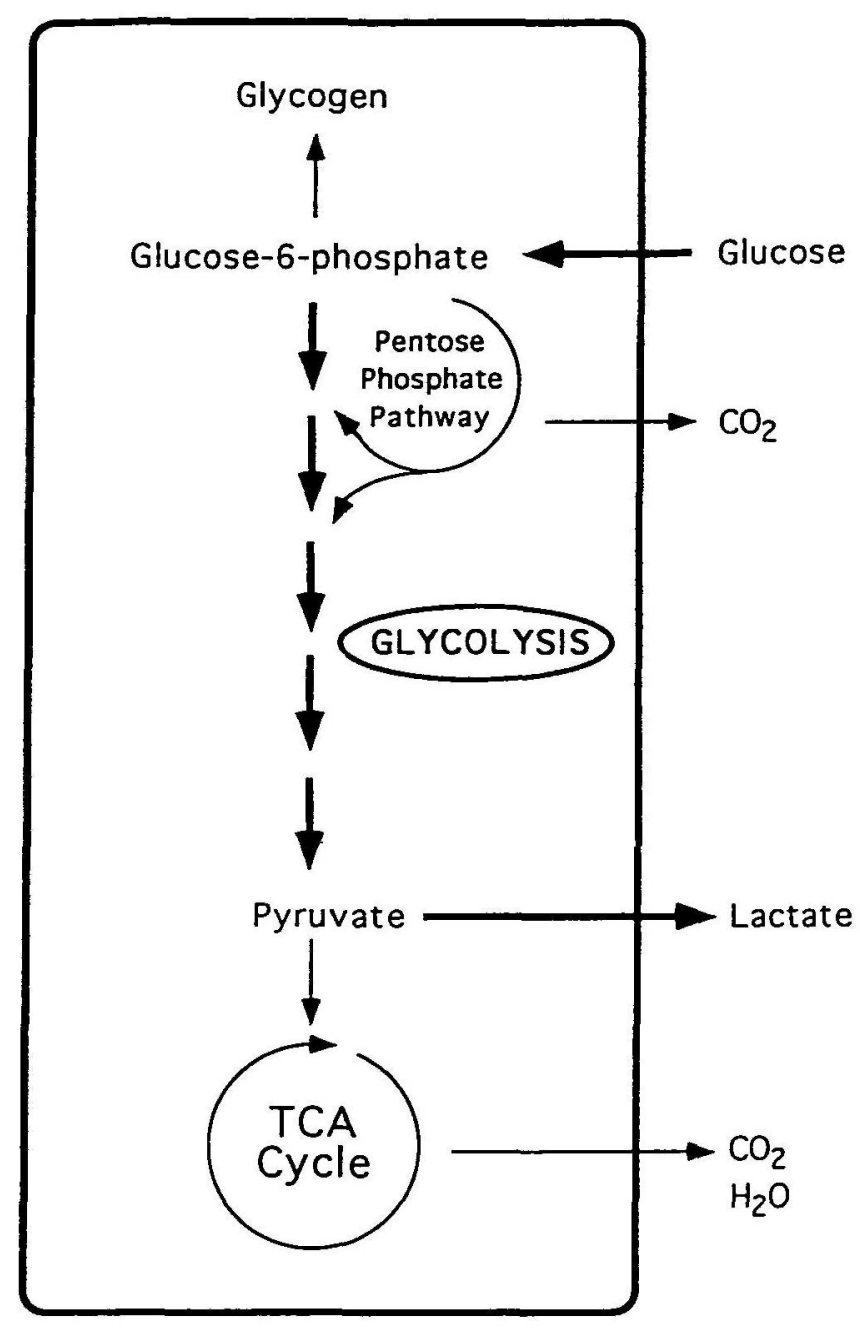

Figure 1. Metabolic pathways for glucose. Glycolysis is shown with thick arrows.

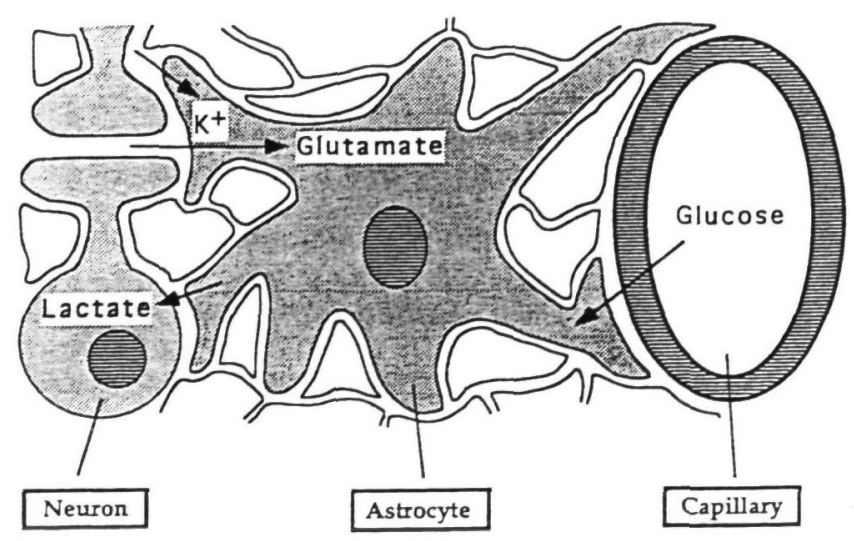

Figure 2 Schematic representation of the cytological relationships between astrocytes, neurons, and blood vessels. Astrocyte end-feet form the first cellular barrier encountered by glucose entering the brain parenchyma and are therefore a likely prevalent uptake site. They are also ideally located to sense synaptic activity, since one of their main function is to remove excess glutamate and potassium from the extracellular space upon neuronal activation. Finally, they can provide neurons with metabolic intermediates such as lactate, which is an adequate energy substrate. where the terminals of axons projecting from the lateral geniculate engage in synaptic contacts (Kennedy et al., 1976). A similar observation was made in the whisker barrel field of rat somatosensory cortex where the increase in glucose utilization during activation is greatest in layers III and IV (Hand et al., 1978). Consistent with this finding, activation studies of specific functional pathways using PET determination of cerebral blood flow indicate that the increases in energy demands occur in the projection areas, that is, where axon terminals are found (Zeki et al., 1991; Deiber et al., 1993).

This set of observations, while providing a focus on synaptic terminals and their associated astrocytic processes as the principal sites of activation-dependent increases in energy metabolism, lack the cellular resolution required to determine the relative contribution of neurons and glial cells as well as the nature of metabolic exchanges occurring between these two cell types. Studies in cellularly homogeneous preparations in conjunction with others on well compartmentalized and simple nervous tissues have provided strong indications for a prevalent glial localization of the activation-induced increase in glucose utilization. These evidences and their relevance to functional brain imaging are reviewed in the following paragraphs.

\section{Cellular Localization of Metabolic Events during Activation}

\section{Cytological Relationships between Neurons and Astrocytes}

When considering brain energy metabolism the focus is predominantly, if not exclusively, placed on neuronal energy metabolism. However, other cell types, namely glia and vascular endothelial cells, play an active role in the flux of energy substrates to neurons. The arguments are both quantitative and qualitative. First, while it is arduous to provide a definitive ratio between neurons and non-neuronal cells, given the variability in figures obtained in various species, brain areas, and developmental ages using often methods that are not easily comparable, it is clear that neurons contribute at most $50 \%$ of cerebral cortical volume (O'Kusky and Colonnier, 1982; Kimelberg and Norenberg, 1989; Bignami, 1991). Estimates of astrocyte:neuron ratios of 10:1 have been put forward (Bignami, 1991). In addition, there is clear evidence indicating that the astrocyte:neuron ratio increases with increasing brain size (Tower and Young, 1973); this is an important consideration when considering the cellular bases of brain energy metabo lism in humans. Second, particular astrocytic profiles, the endfeet, surround intraparenchymal capillaries, which are the source of glucose. This cytoarchitectural arrangement implies that astrocytes form the first cellular barrier that glucose entering the brain parenchyma encounters, and it makes them a likely site of prevalent glucose uptake (Fig. 2). This latter structural feature has long been suggested as evidence indicating a role of astrocytes in the distribution of substances from blood to other brain cells (Sala, 1891; Andriezen, 1893). Finally, astrocyte processes are wrapped around synaptic contacts, implying that they are ideally positioned to sense and be functionally coupled to increased synaptic activity. In fact, two well-established functions of astrocytes are the clearance of potassium and the uptake of glutamate, both of which increase in the extracellular space in conjunction with synaptic activation (Barres, 1991).

\section{Comparison of Glucose Utilization by Astrocytes and Neurons}

\section{Basal Glucose Utilization}

Basal glucose utilization of the gray matter as determined by the 2-DG technique varies, depending on the brain structure, 


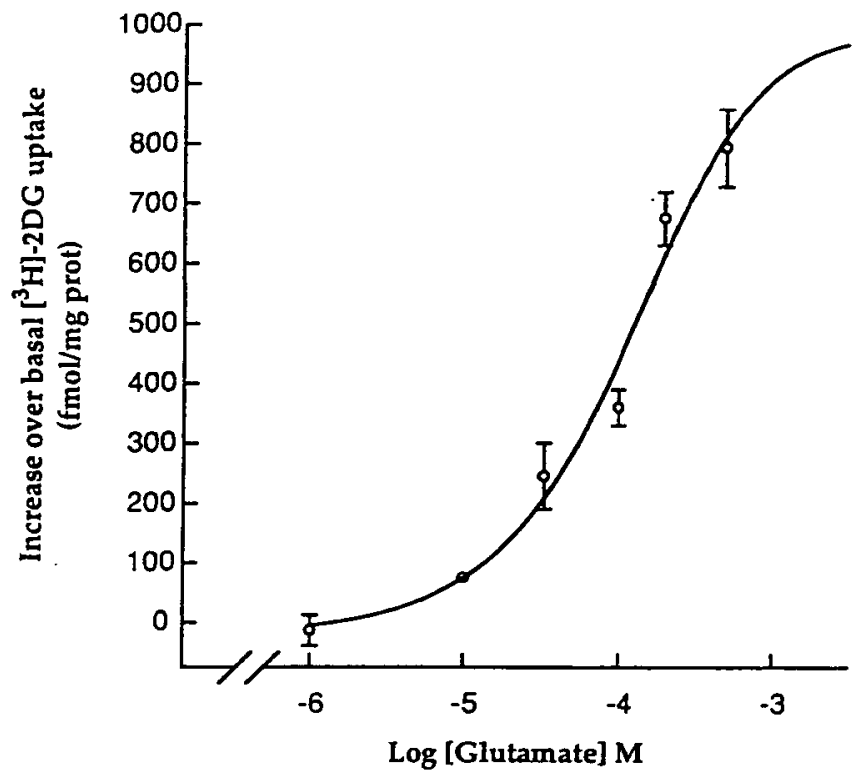

Figure 3. Concentration-response curve of the stimulation by glutamate of $3 \mathrm{H}-20 \mathrm{G}$ uptake by astrocytes. The $\mathrm{EC}_{50}$ of this effect is $80 \mu \mathrm{M}$ (taken with permission from Pellerin and Magistretti, 1994).

between 50 and $150 \mu \mathrm{mol} / 100 \mathrm{gm}$ wet weight/min in the rat (Sokoloff et al., 1977). If a protein content of $10 \%$ of wet weight is assumed, a value of $5-15 \mathrm{nmol} / \mathrm{mg} \mathrm{prot} / \mathrm{min}$ is obtained. These values are approximately $50 \%$ lower in the primate brain (Kennedy et al., 1978). Physiological activation of specific pathways results in a 1.5-3-fold increase in LCMRglu, as determined by the 2-DG technique (Miyaoka et al., 1979 McCulloch et al., 1980). Glucose utilization can be determined with the 2-DG technique in cellularly homogeneous preparations of astrocytes or neurons such as primary cultures pre pared from neonatal or embryonic mouse cerebral cortex. The basal rate of glucose utilization in astrocytes is higher than in neurons, with a rate in astrocytes of $22.3 \mathrm{nmol} / \mathrm{mg}$ $\mathrm{prot} / \mathrm{min}$ and in neurons of $6.3 \mathrm{nmol} / \mathrm{mg}$ prot $/ \mathrm{min}$. These values are of the same order as those determined in vivo for cortical gray matter, with the 2-DG autoradiographic technique (Sokoloff et al., 1977). Thus, in view of this difference and of the quantitative preponderance of astrocytes compared to neurons in the gray matter, these data reveal a significant contribution of astrocytes to basal glucose utilization as determined by 2-DG autoradiography or PET.

\section{Glucose Utilization during Activation}

The contribution of astrocytes to glucose utilization during activation is even more striking. Thus, since during activation of a given cortical area the concentration of glutamate in the extracellular space increases considerably due to its release from the axon terminals of activated pathways (Fonnum, 1984), the effect of glutamate application on glucose utilization by astrocytes and neurons in culture was examined. As shown in Figure 3, L-glutamate stimulates 2-DG uptake and phosphorylation by astrocytes in a concentration-dependent manner, with an $\mathrm{EC}_{30}$ of $80 \mu \mathrm{M}$ (Pellerin and Magistretti, 1994; Takahashi et al., 1995). This effect is not mediated by specific glutamate receptors known to be present on astrocytes (Pearce, 1993), since it is not inhibited by any of the specific antagonists tested nor is it mimicked by agonists specific for each receptor subtype such as NMDA, AMPA, quisqualate, or $t$-ACPD. The effect of glutamate is stereospecific, with only the L-isomer being active, and dependent on the presence of extracellular sodium. This pharmacological profile is charac- teristic of the glutamate transporter (Kanner, 1993). Indeed, the increase in glucose utilization evoked by glutamate is completely abolished by preincubation of the cultures with the potent glutamate transporter inhibitor DL-tbreo- $\beta$-hydroxyaspartate (THA; Pellerin and Magistretti, 1994). These results clearly indicate a tight coupling between $\mathrm{Na}^{+}$-dependent glutamate uptake and glucose utilization by astrocytes (Fig. 4). The intracellular molecular mechanism(s) of this coupling are presently being investigated; a critical involvement of the $\mathrm{Na}^{+} / \mathrm{K}^{+}$-ATPase is likely, since ouabain completely inhibits the glutamate-evoked 2-DG uptake by astrocytes (Pellerin and Magistretti, 1994). The astrocytic $\mathrm{Na}^{+} / \mathrm{K}^{+}$-ATPase responds predominantly to increases in intracellular $\mathrm{Na}^{+}$for which it shows a $K_{m}$ of about $10 \mathrm{~mm}$ (Kimelberg et al., 1978; Erecinska, 1989). Since in cultured astrocytes, the $\left(\mathrm{Na}^{+}\right)$, concentration ranges between 10 and $20 \mathrm{~mm}$ (Kimelberg et al., 1993), $\mathrm{Na}^{+} /$ $\mathrm{K}^{+}$-ATPase is set to be readily activated when $\left(\mathrm{Na}^{+}\right)$, raises concomitantly with glutamate uptake (Bowman and Kimelberg, 1984). In this context, it is important to note that in vivo, the main mechanism that accounts for the activationinduced 2-DG uptake is represented by the activity of the $\mathrm{Na}^{+} / \mathrm{K}^{+}$-ATPase (Mata et al., 1980).

In contrast to what is observed in astrocytes, glutamate does not stimulate 2-DG uptake in cultured neurons, despite the fact that glutamate can elicit functional responses in these cells, which are mediated by ionotropic and metabotropic receptors. Examples of functional responses in these neuronal cultures, which are totally devoid of glial markers, are the NMDA and AMPA/kainate-mediated increases in intracellular calcium (Stella et al., 1995), stimulation of arachidonic acid formation (Stella et al., 1995), and induction of c-fos expression (Pellegri et al., 1994), as well as the metabotropic receptor-mediated stimulation of phospholipase C (Stella et al., 1995). Cultured neurons also possess an active glutamate reuptake system, which has, however, a maximal capacity almost 80 times inferior to that of astrocytes $\left(V_{\max }\right.$ in neurons $0.74 \mathrm{nmol} / \mathrm{mg}$ prot $/ \mathrm{min} ; V_{\max }$ in astrocytes $57.4 \mathrm{nmol} / \mathrm{mg}$ prot/min).

A similar compartmentalization of glucose uptake has been described in a series of elegant experiments carried out by Marcos Tsacopoulos and his colleagues in the honeybee drone retina and, more recently, in the guinea pig retina. The honeybee drone retina is a crystal-like structure that is structurally and metabolically compartmentalized (Tsacopoulos and Veuthey, 1993). Thus, in this highly organized nervous tissue preparation, photoreceptor cells form rosette-like structures that are surrounded by glial cells. In addition, mitochondria are exclusively present in the photoreceptor neurons Upon activation of the photoreceptors by light, an increase in 2-DG uptake can be visualized in the glial cells surrounding the rosettes, but not in the photoreceptors (Tsacopoulos et al., 1988). An increase in $\mathrm{O}_{2}$ consumption is, nonetheless, measured in photoreceptors. These experiments suggest that following activation of photoreceptors by light, glucose is predominantly taken up by glial cells, which then release a metabolic substrate to be oxidized by photoreceptor cells. Similar results have been observed in guinea pig retina, in which 2 DG uptake is visualized by autoradiography only in Müller cells (Poitry-Yamate and Tsacopoulos, 1992).

\section{Lactate Released by Astrocytes Is a Metabolic Substrate for} Neurons

The fact that during activation the increase in glucose uptake can be ascribed predominantly, if not exclusively, to astrocytes, implies that energy substrates other than glucose must be released by astrocytes. As indicated earlier, lactate and pyruvate are adequate substrates for brain tissue in vitro (MCIlwain, 1953; Ide et al., 1969; Teller et al. 1977; Mcllwain and 


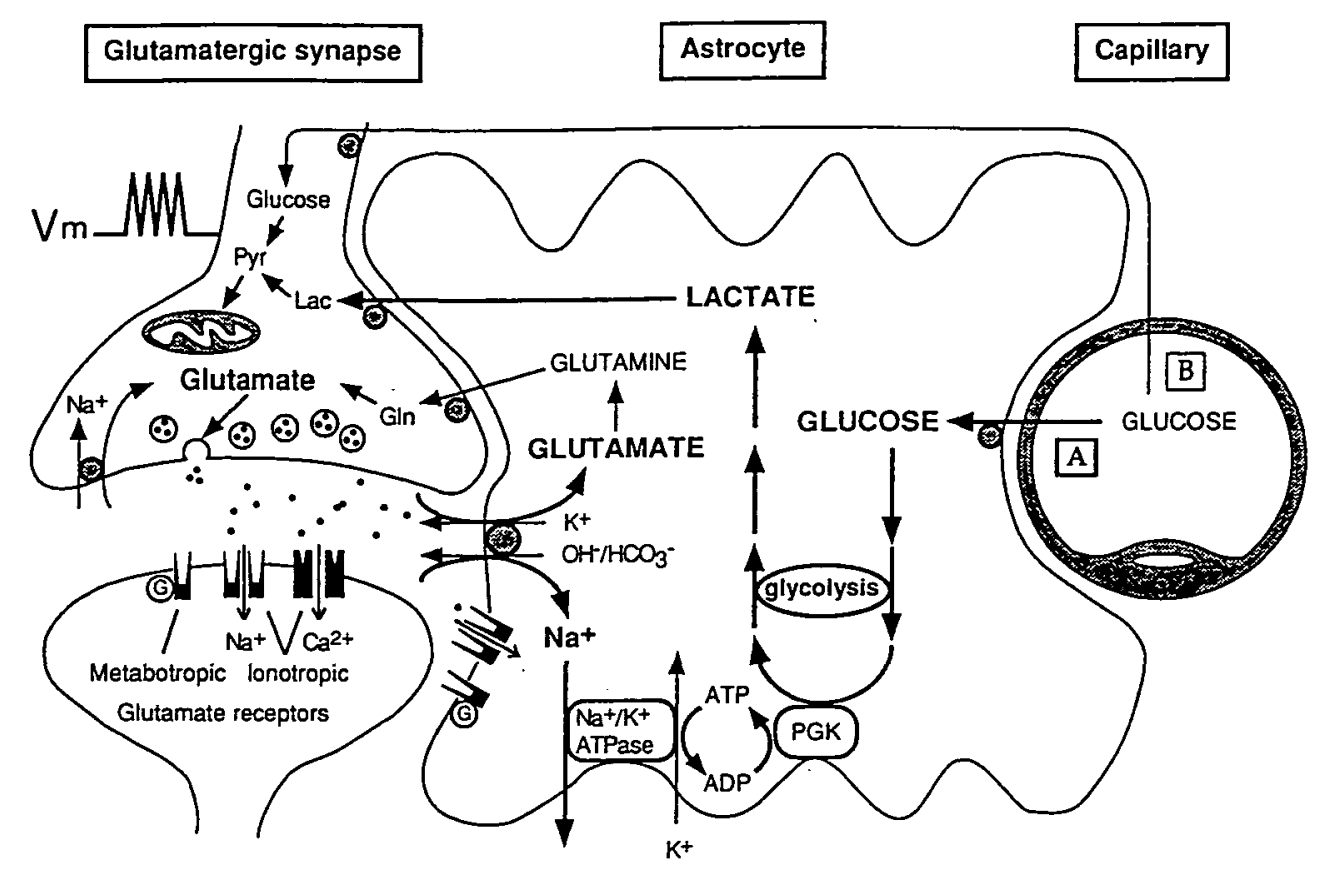

Figure 4. Schematic representation of the mechanism for glutamate-induced glycolysis in astrocytes during physiological activation. At glutamatergic synapses, glutamate depolarizes neurons by acting at specific receptor subtypes. The action of glutamate is terminated by an efficient glutamate uptake system located primarily in astrocytes. Glutamate is cotransported with $\mathrm{Na}^{+}$, resulting in an increase in the intracellular concentration of $\mathrm{Na}^{+}$, leading to an activation of the $\mathrm{Na}^{+} / \mathrm{K}^{+}$ATPase. The pump, fueled by ATP provided by membrane-bound glycolytic enzymes (possibly phosphoglycerate kinase, PGK; see Proverbio and Hoffman, 1977), activates glycolysis, that is, glucose utilization and lactate production, in astrocytes. Lactate, once released, can be taken up by neurons and serve as an adequate energy substrate. For graphic clarity, only lactate uptake into presynaptic terminals is indicated. However, this process could also occur at the postsynaptic neuron. This model, which summarizes in vitro experimental evidences indicating glutamate-induced glycolysis, is taken to reflect cellular and molecular events occurring during activation of a given cortical area (arrow labeled A: activation). Direct glucose uptake into neurons under basal conditions is also shown (arrow labeled B. basal conditions). Pyr, pyruvate; Lac, lactate; Gln, glutamine; G, G-protein (taken with permission from Pellerin and Magistretti, 1994).

Bachelard, 1985; Schurr et al., 1988). In fact, synaptic activity can be maintained in cerebral cortical slices with only lactate or pyruvate as a substrate (Mcllwain, 1953; McIlwain and Bachelard, 1985; Schurr et al., 1988). Recently, neurodegeneration in the hippocampal slice preparation induced by glucose deprivation has been shown to be prevented by inclusion of lactate in the perfusing medium (Izumi et al., 1994). Indeed, recent evidences obtained in cellularly homogeneous or well compartmentalized preparations indicate that astrocytes process glycolytically glucose by converting it to lactate. Thus, lactate is quantitatively the main metabolic intermediate released by cultured astrocytes at a rate of 15 to $30 \mathrm{nmol} / \mathrm{mg}$ prot/min (Walz and Muckerji, 1988; Dringen and Hamprecht, 1993; Sorg et al., 1993). This rate of release correlates well with the rate of glucose uptake by the gray matter (Sokoloff et al., 1977) or by astrocytes in culture (Yarowsky et al., 1986; Yu et al., 1993), which is between 5 and $15 \mathrm{nmol} / \mathrm{mg}$ prot/ min. Other, quantitatively less important intermediates released by astrocytes are pyruvate (approximately 10 times less than lactate), $\alpha$-ketoglutarate, citrate, and malate (Shank and Campbell, 1984; Selak et al., 1985; Sonnewald et al., 1991; Shank et al., 1993). Furthermore, fluxes of endogenous lactate between astrocytes and neurons have been quantified in vitro showing lactate utilization even in the presence of glucose (Larrabee, 1983, 1992). However, in order for lactate (or pyruvate) to be an adequate metabolic substrates for neurons, particularly during activation, two additional conditions have to be fulfilled. First, that, indeed, during activation lactate release by astrocyzes increases; second, lactate uptake by neurons must be demonstrated. Both mechanisms have been recently shown. Thus, when activation is mimicked in in vitro conditions by exposing cultured astrocytes to glutamate, a marked release of lactate, and to a lesser degree, pyruvate, is observed (Pellerin and Magistretti, 1994). This glutamate- evoked lactate release shows the same pharmacology and time course as the glutamate-evoked glucose utilization, thus indicating that glutamate stimulates the processing of glucose through glycolysis (Pellerin and Magistretti, 1994). Consistent with the notion of activation-induced glycolysis are studies indicating increases in lactate levels in the rat somatosensory cortex following forepaw stimulation (Hossmann and Linn, 1987; Ueki et al., 1988). In addition, when lactate was measured in vivo by microdialysis in freely moving rats, similar increases in hippocampus and striatum following somatosensory stimulation were demonstrated (Schasfoort et al., 1988; Fellows et al., 1993). Interestingly, the rate of lactate clearance from the extracellular space was markedly slowed in the presence of tetrodotoxin, a specific blocker of the neuronal voltage-sensitive sodium channels responsible for the generation of action potentials (Fellows et al., 1993). This latter observation implies that during activation, lactate may normally be taken up by neurons as an energy fuel. Indeed, recent evidence obtained in purified neuronal cultures indicates the presence of a saturable and specific transport system for lactate (Dringen et al., 1993b).

Thus, a metabolic compartmentation whereby glucose taken up by astrocytes is metabolized glycolytically to lactate, which is then released in the extracellular space to be utilized by neurons, is consistent with the available biochemical and electrophysiological observations. This array of in vitro and in vivo experimental evidence supports the model of cellspecific metabolic regulation illustrated in Figure 4. In particular, as far as glutamate-induced glycolysis is concerned, this model is taken to reflect cellular and molecular events occurring during activation of a given cortical area. Direct neuronal glucose uptake could still take place under these conditions, as it does in the basal state. It should also be noted that a reciprocal relationship appears to exist between aerobic gly- 
colysis and glutamate uptake. Thus, glutamate uptake into trocytes is markedly decreased by inhibition of glycoly: while being only moderately affected by hypoxia (Swansc 1992). These results suggest the existence of a cooperati mechanism whereby glutamate uptake triggers aerobic $\mathrm{g}$ colysis, which in turn, is necessary to maintain proper tral membrane glutamate and $\mathrm{Na}^{+}$gradients to direct glutama transport into astrocytes.

Studies in the well-compartmentalized honeybee dro: retina and in isolated preparations of guinea pig retina $\mathrm{cc}$ taining photoreceptors attached to Müller cells corrobora such metabolic fluxes between glia and neurons. Thus, in a dition to the glial localization of glucose uptake during ac vation, the release of glycolytic products has also been shor In particular, during activation, glial cells in the honeyb drone retina release alanine produced from pyruvate by tras amination; the released alanine is taken up by photorecept neurons which, after reconversion to pyruvate, can enter $t]$ tricarboxylic acid cycle to yield ATP through oxidative phc phorylation (Tsacopoulos et al., 1994). In the guinea pig $r$ ina, lactate, formed glycolytically from glucose, is released 1 the Müller cells to fuel photoreceptor neurons (Poitry-Yama 1994).

In summary, while plasma lactate cannot fully substitu for glucose as a metabolic substrate for brain because of limited permeability across the blood-brain barrier (Pardrid: and Oldendorf, 1977), lactate formed within the brain pare chyma, e.g., through glutamate-activated glycolysis in ast cytes, can fulfill the energetic needs of neurons. Lactate, aft conversion to pyruvate via a reaction catalyzed by lactate dehydrogenase (LDH), can provide on a molar basis 18 ATP through oxidative phosphorylation. Five isozymes of LDH exist, with at one end the $M_{4}$ (muscle) isozyme favoring the formation of lactate from pyruvate, while the $\mathrm{H}_{4}$ (heart) isozyme drives the reaction preferentially in the opposite direction. The other three isozymes are tetramers composed of different combinations of the two subunits ( $M$ and $H$ ) and have intermediate properties. There is some evidence that the $M$ subunit is predominant in astrocytes, while neurons are enriched with the $H$ subunit (Tholey et al., 1981), an observation consistent with lactate production by astrocytes and utilization by neurons. Interestingly, a similar metabolic exchange between cell types has been described in the testis (Mita and Hall, 1982). In this case, active glycolysis in Sertoli cells produces lactate, which is the preferred metabolic substrate for round spermatids.

\section{Ghycogenolysis Occurs during Activation and Is Localized in Astrocytes}

Glycogen is the single largest energy reserve of the brain; it is mainly localized in astrocytes, although ependymal and choroid plexus cells, as well as certain large neurons in the brain stem contain glycogen (Magistretti et al., 1993). When compared to liver or muscle, the glycogen content of the brain is exceedingly small, about 100 and 10 times inferior, respectively. However, the brain can hardly be considered a glycogen storage organ and here the function of glycogen should be viewed as that of providing a metabolic buffer during physiological activity. Indeed, glycogen turnover in the brain is extremely rapid and glycogen levels are finely coordinated with synaptic activity (Magistretti et al., 1993). Thus, for example, during barbiturate anesthesia, a condition in which synaptic activity is markedly attenuated, glycogen levels raise sharply (Phelps, 1972); interestingly however, the glycogen content of cultures containing exclusively astrocytes is not increased by general anesthetics (Swanson et al., 1989); this observation indicates that the in vivo action of barbiturates on astrocytic glycogen is due to the inhibition of neuronal activity, stressing

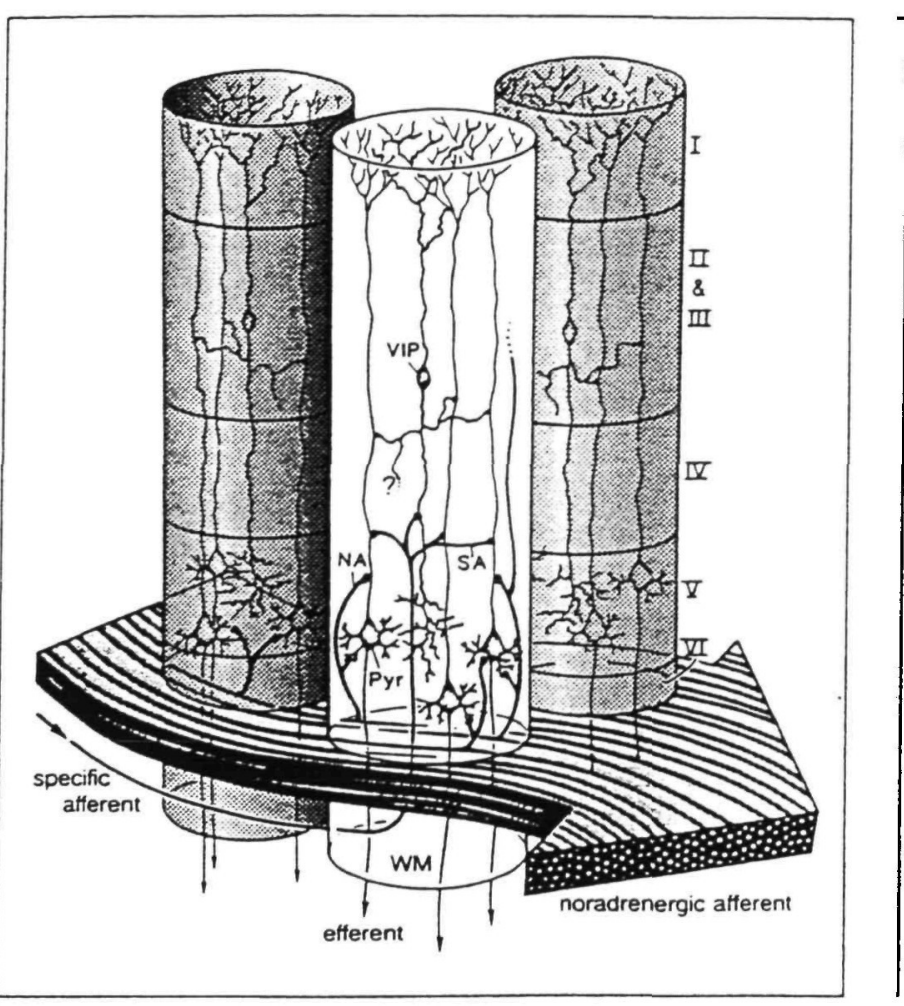

Figure 5. Columnar organization of VIP-containing neurons. VIP, VIP-containing bipolar cells; NA, noradrenergic afferent, Pyr, pyramidal cells furnishing major afferent projections; SA, specific afferent (from the thalamus or from other cortical regions); WM, subcortical white matter. Cortical layers denoted by roman numerals (reprinted from Magistretti and Morrison, 1988, with kind permission from Elsevier Science Ltd. The Boulevard, Langford Lane, Kidlington OX5 1GB, UK).

the existence of a tight coupling between synaptic activity and astrocytic glycogen. In addition, reactive astrocytes, which develop in areas where neuronal activity is decreased or absent as a consequence of injury, contain high amounts of glycogen (Shimizu and Hamuro, 1958; Wolfe et al., 1962; Watanabe and Passonneau, 1974). Glycogen levels are tightly regulated by various neurotransmitters (Magistretti et al., 1993). Thus, we have shown that Vasoactive Intestinal Peptide (VIP), a neurotransmitter contained in a homogeneous population of bipolar, radially oriented neurons (Magistretti and Morrison, 1988) could promote a cAMP-dependent glycogenolysis in mouse cerebral cortical slices (Magistretti et al., 1981). In view of the morphology and arborization pattern of VIP-containing neurons (Fig. 5), we proposed that these cells could regulate the availability of energy substrates locally, within cortical columns (Magistretti et al., 1981; Magistretti and Morrison, 1988). A similar effect had been previously described for NA (Quach et al., 1978), serotonin and histamine (Quach et al., 1980, 1982). The noradrenergic system is organized according to principles strikingly different from those of VIP neurons: the cell bodies of NA-containing neurons are localized in the locus coeruleus in the brain stem from where axons project to various brain areas including the cerebral cortex; here, they enter the rostral end and progress caudally with a predominantly horizontal trajectory, across a vast rostrocaudal expanse of cortex (Morrison et al., 1978). Given these morphological features we suggested that, in contrast to VIP-containing intracortical neurons, the noradrenergic system could regulate energy homeostasis globally, spanning across functionally distinct cortical areas (Magistretti et al., 1981; Magistretti and Morrison, 1988; Fig. 6).

The glycogenolytic effect of VIP and NA is exerted in astrocytes, as indicated by studies in primary astrocyte cultures 


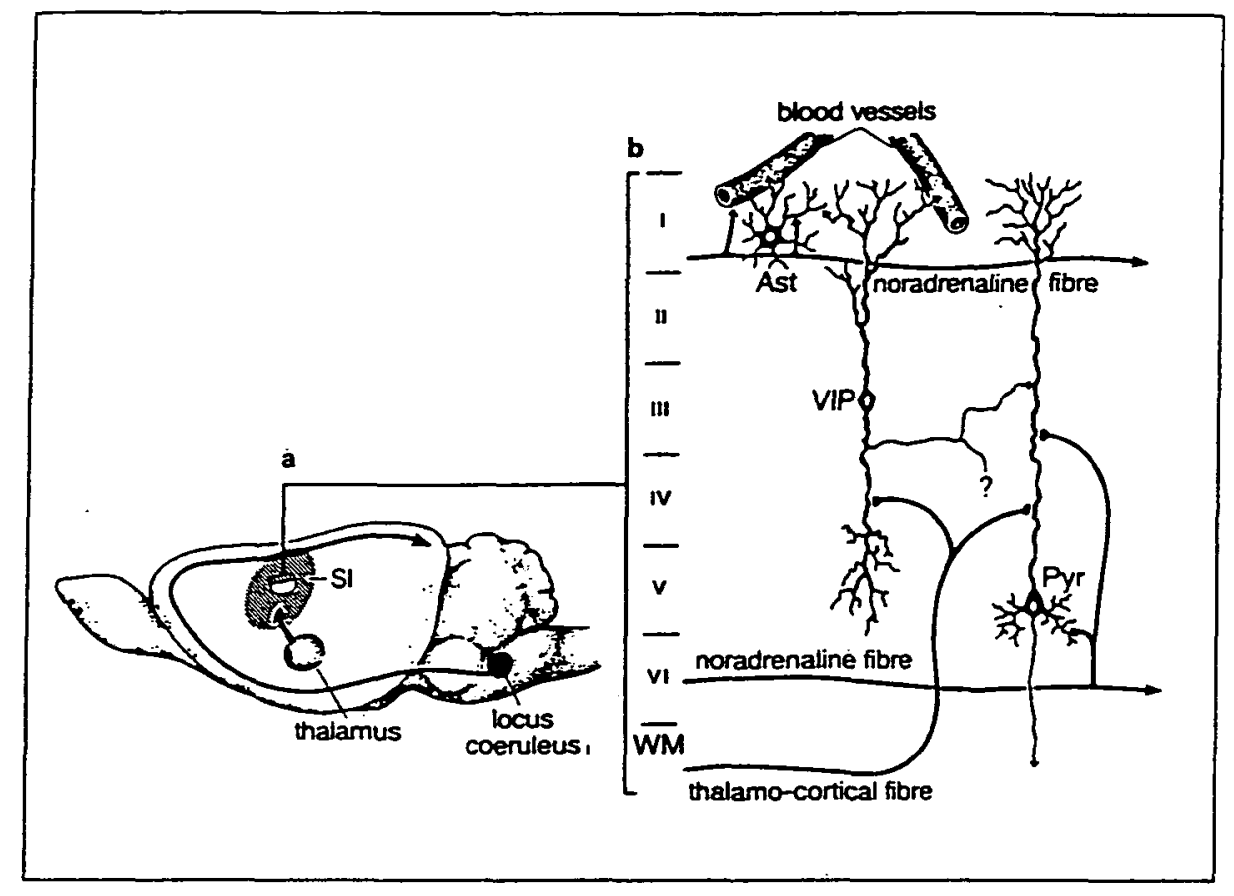

Figure 6. Anatomical organization and putative targets of the NA- and VIP-containing neuronal circuits in rat cerebral cortex a, Noradrenergic fibers originate in locus ceruleus and project to the cerebral cortex, where they adopt a horizontal trajectory parallel to pial surface. $b$, VIP neurons are intrinsic to the cerebral cortex and are oriented vertically, perpendicular to the pial surface. Astrocytes (Ast), intraparenchymal blood vessels, and neurons such as certain pyramidal cells (Pyn are potential target cells for VIP neurons. Roman numerals indicate cortical layers. VIP neurons can be activated by specific afferents (e.g., thalamocortical fibers). SI, primary sensory cortex, WM, white matter (reprinted from Magistretti and Morrison, 1988, with kind permission from Elsevier Science Ltd, The Boulevard, Langford Lane, Kidlington OX5 1GB, UKI.

(Magistretti et al., 1983; Sorg and Magistretti, 1991) as well as by the fact that glycogen is primarily localized in this cell type (Peters et al., 1991). Thus, VIP and NA promote a concentration- and time-dependent glycogenolysis in astrocytes, with $\mathrm{EC}_{50}$ of 3 and $20 \mathrm{nM}$, respectively (Magistretti et al., 1983; Sorg and Magistretti, 1991). The effect of NA is mediated by both $\beta$ and $\alpha_{1}$ receptors. In addition to VIP and NA, adenosine and ATP are also glycogenolytic in astrocytes (Table 1 ). The initial rate of glycogenolysis activated by VIP and NA is between 5 and $10 \mathrm{nmol} / \mathrm{mg}$ prot/min (Sorg and Magistretti, 1991), a value that is remarkably close to glucose utilization of the gray matter, as determined by the 2-DG autoradiographic method (Sokoloff et al., 1977). This correlation indicates that the glycosyl units mobilized in response to the two glycogenolytic neurotransmitters can provide quantitatively adequate substrates for the energy demands of the brain parenchyma. At this stage, it is not yet clear whether the glycosyl units mobilized through glycogenolysis are used by astrocytes to face their energy demands during activation, or whether they are metabolized to a substrate such as lactate (Dringen et al., 1993a), which is then released for the use of neurons. A well-established fact is that glucose is not released by astrocytes, at least in vitro (Dringen et al., 1993a), supporting the view that the activity of glucose-6-phosphatase in astrocytes is very low (Sokoloff et al., 1977; Fishman and Kamovsky, 1986).

\section{Tabis 1}

Glycogenolytic neurotransmitters in primary cultures of mouse cortical astrocytes

\begin{tabular}{lc} 
Substance & $E C_{s 0}$ (nM) \\
\hline VIP & 3 \\
PHI & 6 \\
Secretin & 0.5 \\
PACAP & 0.08 \\
Noraderenaline & 20 \\
Isoproterenol (B) & 20 \\
Methoxamine $\left(\alpha_{1}\right)$ & 600 \\
Adenosine & 800 \\
ATP & 1300 \\
\hline
\end{tabular}

PHI, Peptide histodine isoleucine; PACAP, pituitary adenylate cyclase activating peptide.
Another action of NA on energy metabolism is the marked stimulation of 2-DG uptake in primary astrocyte cultures (Yu et al., 1993). This action is functionally coordinated with glycogenolysis, since the same extracellular signal (NA) results in an increased availability of glycosyl units for ATP production in astrocytes. In contrast to NA, VIP does not influence glucose uptake by astrocytes (Yu et al., 1993).

Glycogenolysis, revealed by a newly developed autoradiography technique for glycogen, has been demonstrated also in vivo following physiological activation of a modality-specific pathway (Swanson et al., 1992). Thus, repeated stimulation of the vibrissae resulted in a marked decrease in the density of glycogen-associated autoradiographic grains in the somatosensory cortex of rats (barrel field) as well as in the relevant thalamic nuclei (Swanson et al., 1992). These observations indicate that the physiological activation of specific neuronal circuits results in the mobilization of glial glycogen stores.

Further evidence supporting a role of astrocytic glycogen as a metabolic buffer in the early stages of activation has been provided in hippocampal slices (Lipton, 1988). Electrical stimulation of the slice results in an immediate and marked increase in NADH fluorescence, an index for the activation of glycolysis (Lipton, 1973). This increase in NADH fluorescence is observed in a well-oxygenated medium containing adequate supplies of glucose, and occurs at the onset of synaptic activity. However, the signal disappears when the glycogen content of the slices is depleted by a glycogenolytic pretreatment (Lipton, 1973). This observation further suggests that an activation of glycogenolysis occurs at the onset of synaptic activity.

\section{Correlations with Functional Brain Imaging}

The data reviewed thus far on the cell-specific metabolic events that take place during activation strongly suggest an activity-dependent glucose uptake into astrocytes, which then release lactate as the metabolic substrate to fuel neuronal energy metabolism. Evidence has also been provided for an activation-induced glycogen mobilization in astrocytes. This set of observations is consistent with some now well-established but originally unexpected findings obtained in functional 
brain imaging studies, for which they provide, in fact, some cellular and molecular bases. With the advent of Positron Emission Tomography (PET) and the use of positron-mitting isotopes such as ${ }^{18} \mathrm{~F}$, local glucose utilization has been studied in humans with $2-\left({ }^{18} \mathrm{~F}\right)$ fluoro-2-deoxyglucose (Phelps et al., 1979; Raichle, 1979; Reivich et al., 1979; Reivich and Alavi, 1983). Similarty, local oxygen consumption and changes in blood flow can be studied in humans by PET using ${ }^{15} \mathrm{O}_{2}$ and $\mathrm{H}_{2}{ }^{15} \mathrm{O}$ (Frackowiak et al., 1980; Raichle et al., 1983). PET studies in which blood flow, oxygen consumption, and glucose utilization were determined in the same subject have now clearly established that focal physiological cortical activation results in a metabolic uncoupling whereby the increases in blood flow and glucose utilization are not matched by a commensurate increase in oxygen consumption, indicating nonoxidative glucose utilization (Fox and Raichle, 1986; Fox et al., 1988). These in vivo observations are consistent with the model of metabolic fluxes summarized in Figure 4, which is based on observations made in purified cellular preparations and in simple and well compartmentalized neural systems. In particular, the glutamate-induced glycolysis recently reported in astrocytes provides a cellular basis for the metabolic uncoupling demonstrated in PET studies, which has led to the notion of activation-induced glycolysis (Fox et al., 1988).

Another important issue that emerges from studies at the cellular level is that glucose utilization, as visualized during physiological activation in humans by PET using ${ }^{18} \mathrm{~F}$-labeled deoxyglucose or in laboratory animals with the 2-DG autoradiography technique may reflect predominantly uptake of the tracer into astrocytes. This conclusion does not question the validity of deoxyglucose-based techniques to map neuronal activity; rather, it provides a cellular and molecular basis for these in vivo imaging procedures.

Evidence for glycolysis as the principal metabolic pathway operational during activation of a given brain area has also been provided by in vivo 'H-NMR spectroscopy studies (Prichard et al., 1991; Sappey-Marinier et al., 1992). Such analyses, which are consistent with the previously reviewed evidences obtained in microdialysis studies (Fellows et al., 1993), show increases in the lactate signal in primary visual cortex following physiological activation (Prichard et al.; 1991; Sappey-Marinier et al., 1992). These in vivo 'H-NMR spectroscopy studies taken together with the PET data indicating a metabolic uncoupling, reveal a previously unrecognized prevalence of glycolysis over oxidative phosphorylation during activation. One of the possible roles for activation-induced glycolysis may be to provide ATP to fuel energy-dependent ion transport, in particular the $\mathrm{Na}^{+} / \mathrm{K}^{+}$-ATPase, which represents the main energy-consuming process in neural cells (Siesjö, 1978; Erecinska and Dagani, 1990). In fact, a preferential role of glycolysis-derived ATP for the activity of the $\mathrm{Na}^{+} / \mathrm{K}^{+}-\mathrm{ATP}$ ase, has been recognized in various tissues (Proverbio and Hoffman, 1977; Paul et al., 1979, 1989), including the brain (Lipton and Robacker, 1983). Other energy-consuming processes in the nervous system appear to use preferentially glycolytically derived ATP (Knull, 1978; Dirks et al., 1980; Raffin et al., 1992; Andersen and Marmarou, 1992).

The conclusions derived from functional brain imaging studies (Fox and Raichle, 1986; Ueki et al., 1988; Prichard et al., 1991; Sappey-Marinier et al., 1992) and from analyses at the cellular level, which indicate that the mammalian brain normally shifts to glycolysis as a source of energy during brief increases in neuronal activity, have formed the basis for the development of the now increasingly popular imaging technique of functional magnetic resonance imaging (MRI; Ogawa et al., 1992; Kwong et al., 1992; Cohen and Bookheimer, 1994; Raichle, 1994). This technique is based on the fact that the magnetic-susceptibility properties of hemoglobin vary with its degree of oxygen saturation (Ogawa et al., 1990). Physiological stimulation results in increased blood flow, implying increased delivery of oxyhemoglobin; however, because of the prevalent glycolytic utilization of glucose in the activated area, oxygen consumption does not increase in parallel. Given this local temporary mismatch between oxygen supply and oxygen consumption, it follows that paradoxically, hemoglobin present in the venous blood draining the activated focus is less desaturated than in surrounding areas. The change in oxy-/deoxy hemoglobin ratio due to the presence of an excess oxyhemoglobin yields a distinct signal detected by MRI (Ogawa et al. 1992; Kwong et al., 1992); this is one of the current molecular mechanisms proposed as a basis for functional MRI (Cohen and Bookheimer, 1994; Raichle, 1994). Other processes, such as, for example, blood volume increase, may also contribute to the signal (Cohen and Bookheimer, 1994). In fact, the nature of the signal detected by functional MRI has also been recently compared to that of signals obtained using optical imaging techniques at the brain surface during functional activation in laboratory animals (Grinvald et al., 1986; Frostig et al., 1990). The view that has emerged from these studies is that at least one of the signals detected with the particular imaging technique of reflectance is due to the presence of deaxybemoglobin in the activated area (Bonhoeffer and Grinvald, 1993), a view that is at odds with the notion of metabolic uncoupling yielding excess axybemoglobin during activation. Below, we provide a few considerations that may offer some useful arguments for the discussion on these contrasting views.

Some Theoretical Considerations on the Nature of the Signals Detected in Optical Imaging Studies during Activation and Their Relationship to Functional MRI

Changes in tissue optical properties that correlated with metabolic activity were first described almost 70 years ago (Kelin, 1925). Since these intrinsic optical signals were relatively small, it is not until recently that, with the advent of appropriate amplification procedures, they have been usefully exploited to study brain activation. Although it was shown that transmission of infrared light could be used to monitor blood volume changes and hemoglobin oxygenation state in the intact brain (Jöbsis, 1977), the technique using the reflectance signal from light at wavelengths between 480 and $940 \mathrm{~nm}$ has been more extensively studied and developed (Grinvald et al., 1988). The nature of the events giving rise to the reflectance signal has not been entirely elucidated, but at least two components have been identified. The first one is the absorption by hemoglobin over almost the entire wavelength range from 480 and 940 , which appears to correlate with changes in blood volume. The second, which becomes predominant between $600-630 \mathrm{~nm}$, appears to correspond to the transition of oxyhemoglobin to deoxyhemoglobin, and would thus reflect oxygen delivery (Frostig et al., 1990).

When the time course of the reflectance signal obtained at different wavelengths following activation is compared, it becomes clear that the signal detected at $600 \mathrm{~nm}$ precedes the signal at either 570 or $840 \mathrm{~nm}$ (Frostig et al., 1990). This was interpreted as an indication that oxygen delivery begins before the increase in blood volume takes place. Since the early signal, which has a latency between 100 and $300 \mathrm{msec}$ is currently used as an index of neuronal activation (Bonhoeffer and Grinvald, 1993), the notion that the origin of the signal detected in optical imaging studies is deoxyhemoglobin has been the prevailing one. A point that is important to note is the fact that, after the initial rise, the signal at $600 \mathrm{~nm}$ decreases while the signal at 570 and $840 \mathrm{~nm}$ begins to increase (Fig. 7). Even more striking is the fact that if the stimulus causing the activation is of short duration, the signal at 


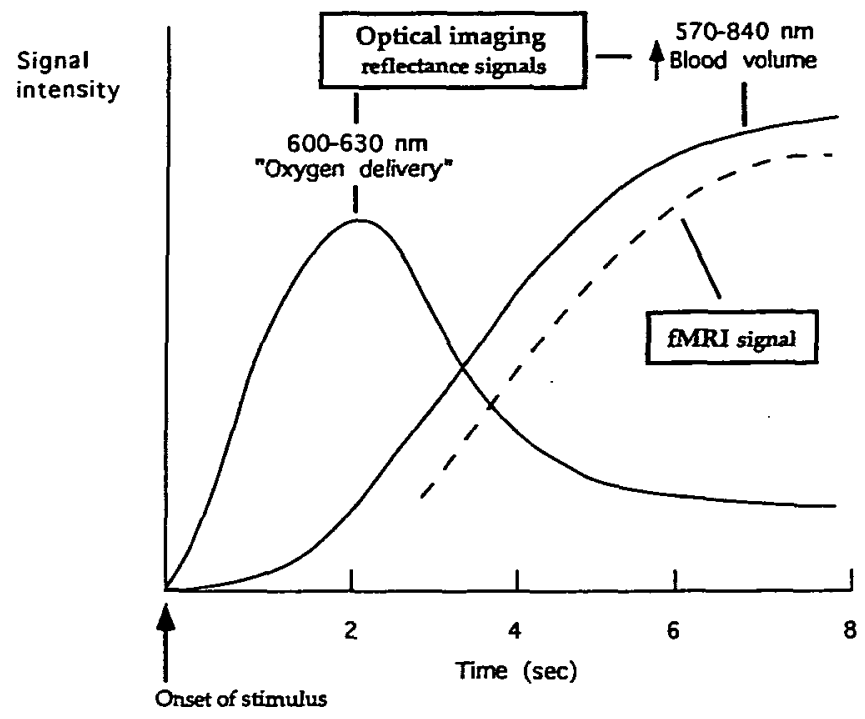

Figure 7. Temporal characteristics of reflectance signals obtained by optical imaging and the $f M R l$ signal. The optical imaging signal recorded at $600-630 \mathrm{~nm}$ is taken to reflect primarily the ratio of $\mathrm{Hb} / \mathrm{HbO}$. Thus, an increase in signal is interpreted as net "oxygen delivery." However, at these wavelengths the signal could theoretically originate from deoxyhemoglobin $(\mathrm{Hb})$ as well as from either nitrosylhemoglobin ( $\mathrm{HbNO}$ ) or methemoglobin [met(III) Hb; see text and Fig. 8, for treatment of this point]. The optical signal recorded either at 570 or $840 \mathrm{~nm}$ is accounted for by the increase in total hemoglobin $\left(\mathrm{Hb}+\mathrm{HbO}_{2}\right)$, a likely consequence of increased blood volume. The fMRi signal is interpreted as an increase in the ratio of $\mathrm{HbO} / \mathrm{Hb}$, a consequence of the increased blood volume with little or no increase in oxygen consumption by the tissue during activation, which leads to a higher oxyhemoglobin content in the venous blood.

$600 \mathrm{~nm}$ shows an undershoot (Grinvald et al., 1986). Since the $600 \mathrm{~nm}$ signal is taken to reflect predominantly the ratio of deoxyhemoglobin over oxyhemoglobin, the decrease and following undershoot could be interpreted either as the reoxygenation of hemoglobin, or more likely, as the arrival of large amounts of oxyhemoglobin overcoming the smaller desaturation process taking place. This, of course, would be brought about by the increase in blood volume that occurs upon activation (Fox and Raichle, 1986; Fox et al., 1988). As a net result, during the undershoot phase, it can be predicted that the blood leaving the activated area would have an higher oxygen content than at rest. This is precisely what is observed with functional magnetic resonance imaging (fMRI), a technique based, as noted earlier, on the difference in magnetic susceptibility between oxyhemoglobin and deoxyhemoglobin (Cohen and Bookheimer, 1994; Raichle, 1994). The latency of $\mathrm{fMRI}$ is longer than optical imaging, that is, a few seconds compared to a few hundred milliseconds (Frostig et al., 1990; Cohen and Bookheimer, 1994; Menon et al., 1994); this would explain why fMRI monitors only the increase in the oxyhemoglobin signal concomitant with the increase in blood volume (Fig. 7). This interpretation on the origin of the reflectance and fMRI signals would agree with PET measurements of blood flow and $\mathrm{O}_{2}$ consumption (Fox and Raichle, 1986; Fox et al., 1988) which indicate an important increase in blood flow upon activation with only a small increase in $\mathrm{O}_{2}$ consumption.

The mechanism that gives rise to both the early increase in oxygen delivery and to the subsequent increase in blood volume recorded by optical imaging still remains to be fully elucidated. Since the initial proposal by Roy and Sherrington (1890) suggesting that products of cerebral metabolism could be responsible for the coupling of neuronal activity to blood flow, a number of candidates have been identified, including $\mathrm{H}^{+}, \mathrm{K}^{+}$and adenosine (Edvinsson et al., 1993). The latest po- tential candidate on the list is the gas nitric oxide (NO), although variable results were obtained from studies in which inhibition of NO synthesis was achieved to prevent the activation-induced increase in local blood flow (Iadecola et al., 1994). However, recent evidence has provided indication that $\mathrm{NO}$, formed through the action of glutamate released during neuronal activation, can, indeed, couple activation to blood flow in the cerebellum (Akgören et al., 1994).

Much less is known about the mechanism(s) responsible for oxygen delivery. One possibility is that local increases in oxygen consumption by the active neuropil triggers oxygen release from hemoglobin by establishing a $\mathrm{pO}_{2}$ gradient. However, PET studies show only marginal increases in oxygen consumption in activated brain areas (Fox et al., 1988). In peripheral tissues such as muscle, a well-known mechanism responsible for oxygen release during increased metabolic demands is the Bohr effect (Stryer, 1988). Actively metabolizing tissues, such as muscle, produce large amounts of $\mathrm{CO}$, and $\mathrm{H}^{+}$. Both agents bind to hemoglobin and decrease its affinity for oxygen, thus causing a local oxygen delivery. A similar mechanism is likely to take place in the brain. In particular, lactate, produced as a consequence of glycolysis-induced activation (Fox et al., 1988; Prichard et al., 1991; Pellerin and Magistretti, 1994) could provide the necessary $\mathrm{H}^{+}$. One problem with this mechanism is that it appears too slow to account for the rapid oxygen delivery signal observed with optical imaging. Another possibility which, to our knowledge, has not been considered so far, is NO production. This gas is produced during activation (Akgören et al., 1994; Iadecola et al., 1994) and diffuses rapidly through biological tissues (Vanderkooi et al., 1994). NO has been shown both in free oxyhemoglobin solutions or in erythrocyte suspensions to react with oxyhemoglobin (Henry et al., 1993). Indeed, based on this well-characterized interaction, hemoglobin is routinely used as an inhibitor of NO's actions since it prevents NO to interact with other molecular targets (Gibson and Roughton, 1957; Martin et al., 1986; Moncada et al., 1991). The interaction of NO with hemoglobin can yield two products: methemoglobin or nitrosylhemoglobin (Henry et al., 1993). Methemoglobin results from the oxidation of oxyhemoglobin by NO (in this reaction, the iron atom in the heme ring is oxidized from $\mathrm{Fe}^{2+}$ to $\mathrm{Fe}^{3+}$; indeed, the spectral changes of oxyhemoglobin to methemoglobin are used to determine NO formation in tissues (Kelm and Schrader, 1990). In contrast nitrosylhemoglobin results from the binding of NO to the heme ring of either deoxyhemoglobin or methemoglobin (Kanner et al., 1992). NO was also shown to bind with a much greater affinity to the hemoprotein than $\mathrm{O}_{2}$. (Henry et al., 1993). An isosbestic point, that is, the wavelength at which two molecules have identical absorbance properties, exists among nitrosylhemoglobin, methemoglobin, and deoxyhemoglobin at around $600 \mathrm{~nm}$ (Van Assendelft, 1970; Kanner et al., 1992). This is the wavelength at which the signal detected by optical imaging is interpreted as oxygen delivery (Frostig et al., 1990). However, a signal detected at $600 \mathrm{~nm}$ can be due to an increase in either nitrosylhemoglobin, methemoglobin, or deoxyhemoglobin, or a combination of them (Fig. 8). Since the early reflectance signal during activation is largest at 605 $\pm 10 \mathrm{~nm}$ (Bonhoeffer and Grinvald, 1993), the possibility should be considered that the optical signal may arise from nitrosylhemoglobin and/or methemoglobin formed by the reaction of NO with hemoglobin. This point is particularly worth considering in view of the fact that PET studies indicate only a marginal increase in oxygen consumption upon activation, hence, making the formation of significant amounts of deoxyhemoglobin unlikely. These considerations bring into perspective a possible role of NO in the early signal 


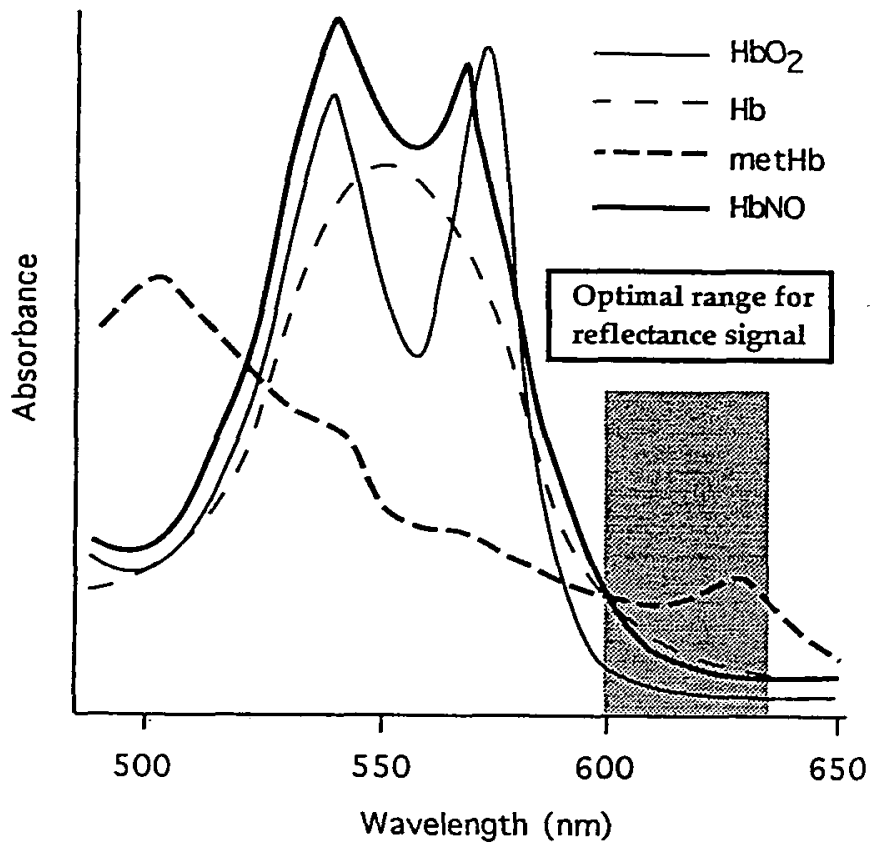

Figure 8. Absorption spectra of oxyhemoglobin $\left(\mathrm{HbO}_{2}\right)$, deoxyhemoglobin $(\mathrm{Hb})$, methemoglobin (metHb), and nitrosylhemoglobin (HbNO; adapted from Van Assendelt, 1970, and Kanner et al., 1992).

detected by optical imaging techniques (Grinvald et al., 1986; Frostig et al., 1990).

\section{Concluding Remarks}

The focus of this article has been to try to highlight the latest observations of brain energy metabolism at the cellular and molecular levels and their relationships with the recent developments in functional brain imaging. From the convergence of in vitro and in vivo observations, a novel emerging concept is that the brain resorts to glycolysis to face increased energy demands during activation. Astrocytes appear to be the predominant cellular locus of this process. The activationinduced glycolysis provides the signal for ${ }^{18} \mathrm{~F}-2 \mathrm{DG}$ studies, ${ }^{\prime} \mathrm{H}-$ NMR lactate spectroscopy, and, ultimately, fMRI. Therefore while the cellular and even molecular basis for these three signals appears to be reasonably clarified, the nature of the molecular mechanism(s) that underlie the coupling between activation and increased blood flow is still elusive, even 100 years after the seminal work of Roy and Sherrington (1890).

\section{Notes}

This article is dedicated to the memory of Amico Bignami, who made fundamental contributions to the field of astrocyte biology. We thank Dr. J.-L. Martin for stimulating discussions and Drs. N. and O. Schaad for useful references concerning NO. This work was supported by Fonds National de la Recherche Scientifique Grant 31-40565.94 to P.J.M.

Address correspondence to Pierre J. Magistretti, M.D., Ph.D., Institut de Physiologie, Faculté de Médecine, Université de Lausanne, 7 , Rue du Bugnon, CH-1005 Lausanne, Switzerland.

\section{References}

Akgören N, Fabricius M, Lauritzen M (1994) Importance of nitric oxide for local increases of blood flow in rat cerebellar cortex during electrical stimulation. Proc Natl Acad Sci USA 91:59035907.

Andersen BJ, Marmarou A (1992) Functional compartmentalization of energy production in neural tissue. Brain Res 585:190-195.

Andriezen WL (1893) On a system of fbre-like cells surrounding the blood vessels of the brain of man and mammals, and its physio logical significance. Int Monatsschr Anat Physiol 10:532-540.
Barres BA (1991) New roles for glia. J Neurosci 11:3685-3694.

Bignami A (1991) Discussions in neuroscience, Vol 8, Glial cells in the central nervous system, pp 1-45. Amsterdam: Elsevier.

Bonhoeffer T, Grinvald A (1993) The layout of iso-orientation domains in area 18 of cat visual cortex: optical imaging reveals a pinwheel-like organization. J Neurosci 13:4157-4180.

Bowman CL, Kimelberg HK (1984) Excitatory amino acids directly depolarize rat brain astrocytes in primary culture. Nature 311 656-659.

Cohen MS, Bookheimer SY (1994) Localization of brain function us ing magnetic resonance imaging. Trends Neurosci 17:268-277.

Cohen PJ, Alexander SC, Smith FC, Reivich M, Wollman H (1967) Effects of hypoxia and normocabia on cerebral blood flow and metabolism in conscious man. J Appl Physiol 23:183-189.

Deiber MP, Pollak P, Passingham R, Landais P, Gervason C, Cinotti L, Friston K, Frackowiak R, Mauguière F, Benabid AL (1993) Thalamic stimulation and suppression of parkinsonian tremor. Brain 116: 267-279.

Dirks B, Hanke J, Krieglstein J, Stock R, Wickop G (1980) Studies on the linkage of energy metabolism and neuronal activity in the isolated perfused rat brain. J Neurochem 35:311-317.

Dringen R, Hamprecht B (1993) Differences in glycogen metabolism in astroglia-rich primary cultures and sorbitol-selected astroglial cultures derived from mouse brain. Glia 8:143-149.

Dringen R, Gebhardt R, Hamprecht B (1993a) Glycogen in astrocytes: possible function as lactate supply for neighboring cells. Brain Res 623:208-214.

Dringen R, Wiesinger H, Hamprecht B (1993b) Uptake of L-lactate by cultured rat brain neurons. Neurosci Lett 163:5-7.

Edvinsson L, MacKenzie ET, McCulloch J (1993) Cerebral blood flow and metabolism, pp 161-162. New York: Raven.

Erecinska $M$ (1989) Stimulation of the $\mathrm{Na}^{+} / \mathrm{K}^{+}$pump activity during electrogenic uptake of acidic amino acid transmitters by rat brain synaptosomes. J Neurochem 52:135-139.

Erecinska M, Dagani F (1990) Relationships between the neuronal sodium/potassium pump and energy metabolism-effects of $\mathrm{K}^{+}$, $\mathrm{Na}^{+}$, and adenosine triphosphate in isolated brain synaptosomes. J Gen Physiol 95:591-616.

Fellows LK, Boutelle MG, Fillenz M (1993) Physiological stimulation increases nonoxidative glucose metabolism in the brain of the freely moving rat. J Neurochem 60:1258-1263.

Fishman RS, Karnovsky ML (1986) Apparent absence of a translocase in the cerebral glucose-6-phosphatase system. J Neurochem 46 : 371-378.

Folbergrova J (1974) Energy metabolism of mouse cerebral cortex during homocysteine convulsions. Brain Res 81:443-454.

Fonnum F (1984) Glutamate: a neurotransmitter in mammalian brain J Neurochem 42:1-11.

Fox PT, Raichle ME (1986) Focal physiological uncoupling of cerebral blood flow and oxidative metabolism during somatosensory stimulation in human subjects. Proc Natl Acad Sci USA 83:11401144.

Fox PT, Raichle ME, Mintun MA, Dence C (1988) Nonoxidative glucose consumption during focal physiologic neural activity. Science 241:462-464.

Frackowiak RSJ, Lenzi GL, Jones T, Heather JD (1980) Quantitative measurement of regional cerebral blood flow and oxygen metabolism in man using ${ }^{15} \mathrm{O}$ and positron emission tomography: theory, procedure and normal values.J Comput Assist Tomogr 4:727-736.

Frostig RD, Lieke EE, Ts'o DY, Grinvald A (1990) Cortical functional architecture and local coupling between neuronal activity and the microcirculation revealed by in vivo high-resolution optical imaging of intrinsic signals. Proc Natl Acad Sci USA 87:6082-6086.

Gibson QH, Roughton FJW (1957) The kinetics and equilibria of the reactions of nitric oxide with sheep haemoglobin. J Physiol (Lond) 136:507-526.

Ginsberg MD, Dietrich WD, Busto R (1987) Coupled forebrain increases of local cerebral glucose utilization and blood flow during physiologic stimulation of a somatosensory pathway in the rat: demonstration by double-label autoradiography. Neurology 37:1119.

Grinvald A, Lieke E, Frostig RD, Gilbert CD, Wiesel TN (1986) Functional architecture of cortex revealed by optical imaging of intrinsic signals. Nature 324:361-364. 
Grinvald A, Frostig RD, Lieke E, Hildesheim R (1988) Optical imaging of neuronal activity. Physiol Rev 68:1285-1366.

Hand PJ, Greeberg JH, Miselis RR, Weller WL, Reivich M (1978) A normal and altered column: a quantitative and qualitative $\left({ }^{1} \mathrm{C}\right)-2$ deoxyglucose (2DG) mapping study. Soc Neurosci Abstr 4:553.

Henry Y, Lepoivre M, Drapier J-C, Ducrocq C, Boucher J-L, Guissani A (1993) EPR characterization of molecular targets for NO in mammalian cells and organelles. FASEB J 7:1124-1134.

Hossmann KA, Linn F (1987) Regional energy metabolism during functional activation of the brain. J Cereb Blood Flow Metab 7: S297-S290.

Iadecola C, Pelligrino DA, Moskowitz MA, Lassen NA (1994) Nitric oxide synthase inhibition and cerebrovascular regulation.J Cereb Blood Flow Metab 14:175-192.

Ide T, Steinke J, Cahill GF Jr (1969) Metabolic interactions of glucose, lactate, and B-hydroxybutyrate in rat brain slices. Am J Physiol 217:784-792.

Izumi Y, Benz AM, Zorumski CF, Olney JW (1994) Effects of lactate and pyruvate on glucose deprivation in rat hippocampal slices. Neuroreport 5:617-620.

Jöbsis FF (1977) Noninvasive, infrared monitoring of cerebral and myocardial oxygen sufficiency and circulatory parameters. Science 198:1264-1267.

Kadekaro M, Crane AM, Sokoloff L (1985) Differential effects of electrical stimulation of sciatic nerve on metabolic activity in spinal cord and dorsal root ganglion in the rat. Proc Natl Acad Sci USA 82:6010-6013.

Kanner BI (1993) Glutamate transporters from brain: a novel neurotransmitter transporter family. FEBS Lett 325:95-99.

Kanner J, Harel S, Granit R (1992) Nitric oxide, an inhibitor of lipid oxidation by lipoxygenase, cyclooxygenase and hemoglobin. Lipids 27:46-49.

Keevil T, Mason HS (1978) Molecular oxygen in biological oxidations-an overview. Methods Enzymol 52:3-40.

Kelin D (1925) On cytochrome, a respiratory pigment, common to animals, yeast, and higher plants. Proc $R$ Soc Lond [Biol] 98:312339.

Kelm M, Schrader J (1990) Control of coronary vascular tone by nitric oxide. Circ Res 66:1561-1575.

Kennedy C, Des Rosiers MH, Sakurada O, Shinohara M, Reivich M, Jehle JW, Sokoloff L (1976) Metabolic mapping of the primary visual system of the monkey by means of the autoradiographic $\left[{ }^{14} \mathrm{C}\right]$ deoxyglucose technique. Proc Natl Acad Sci USA 73:42304234.

Kennedy C, Sakurada O, Shinohara M, Jehle J, Sokoloff L (1978) Local cerebral glucose utilization in the normal conscious macaque monkey. Ann Neurol 4:293-301.

Kety SS (1957) The general metabolism of the brain in vivo. In: The metabolism of the nervous system (Richter D, ed), p 221. London: Pergamon.

Kety SS, Schmidt CF (1948) The nitrous oxide method for the quantitative determination of cerebral blood flow in man: theory, procedure, and normal values. J Clin Invest 27:476-483.

Kimelberg HK, Norenberg MD (1989) Astrocytes. Sci Am 260:4452.

Kimelberg HK, Biddlecome S, Narumi S, Bourke RS (1978) ATPase and carbonic anhydrase activities of bulk-isolated neuron, glia and synaptosome fractions from rat brain. Brain Res 141:305-323.

Kimelberg HK, Jalonen T, Walz W (1993) Regulation of brain microenvironment: transmitters and ions. In: Astrocytes: pharmacology and function (Murphy S, ed), p 193. San Diego: Academic.

Klatt P, Schmidt K, Uray G, Mayer B (1993) Multiple catalytic functions of brain nitric oxide synthase. J Biol Chem 268:1478114787.

Knull HR (1978) Association of glycolytic enzymes with particulate fractions of nerve endings. Biochim Biophys Acta 522:1-9.

Kwong KK, Belliveau JW, Chesler DA, Goldberg IE, Weisskoff RM, Poncelet BP, Kennedy DN, Hoppel BE, Cohen MS, Tumer R, Cheng H$M$, Brady TJ, Rosen BR (1992) Dynamic magnetic resonance imaging of human brain activity during primary sensory stimulation. Proc Natl Acad Sci USA 89:5675-5679.

Larrabee MG (1983) Lactate uptake and release in the presence of glucose by sympathetic ganglia of chicken embryos and by neuronal and nonneuronal cultures prepared from these ganglia. J Neurochem 40:1237-1250.
Larrabee MG (1992) Extracellular intermediates of glucose metabolism: fluxes of endogenous lactate and alanine through extracellular pools in embryonic sympathetic ganglia. J Neurochem 59: $1041-1052$

Lipton P (1973) Effects of membrane depolarization on nicotinamide nucleotide fluorescence in brain slices. Biochem $J$ 136:9991009.

Lipton P (1988) Regulation of glycogen in the dentate gyrus of the in vitro guinea pig hippocampus; effect of combined deprivation of glucose and oxygen. J Neurosci Methods 28:147-154.

Lipton $\mathrm{P}$, Robacker $\mathrm{K}$ (1983) Glycolysis and brain function: $\left[\mathrm{K}^{+}\right]_{0}$ stimulation of protein synthesis and $\mathrm{K}^{+}$uptake require glycolysis. FASEB J 42:2875-2880.

Magistretti PJ, Morrison JH (1988) Noradrenaline- and vasoactive intestinal peptide-containing neuronal systems in neocortex: functional convergence with contrasting morphology. Neuroscience 24:367-378

Magistretti PJ, Morrison JH, Shoemaker WJ, Sapin V, Bloom FE (1981) Vasoactive intestinal polypeptide induces glycogenolysis in mouse cortical slices: a possible regulatory mechanism for the local control of energy metabolism. Proc Natl Acad Sci USA 78:6535-6539.

Magistretti PJ, Manthorpe M, Bloom FE, Varon S (1983) Functional receptors for vasoactive intestinal polypeptide in cultured astroglia from neonatal rat brain. Regul Pept 6:71-80.

Magistretti PJ, Sorg O, Martin J-L (1993) Regulation of glycogen metabolism in astrocytes: physiological, pharmacological, and pathological aspects. In: Astrocytes: pharmacology and function (Murphy S, ed), pp 243-265. San Diego: Academic.

Martin W, Smith JA, White DG (1986) The mechanisms by which haemoglobin inhibits the relaxation of rabbit aorta induced by nitrovasodilators, nitric oxide, or bovine retractor penis inhibitory factor. Br J Pharmacol 89:563-571.

Mata M, Fink DJ, Gainer H, Smith CB, Davidsen L, Savaki H, Schwartz WJ, Sokoloff L (1980) Activity-dependent energy metabolism in rat posterior pituitary primarily reflects sodium pump activity. $\mathrm{J}$ Neurochem 34:213-215.

McCulloch J, Savaki HE, McCulloch MC, Sokoloff L (1980) Retinadependent activation by apomorphine of metabolic activity in the superficial layer of the superior colliculus. Science 207:313-315.

Mcllwain H (1953) Substances which support respiration and metabolic response to electrical impulses in human cerebral tissues. J Neurol Neurosurg Psychiatry 16:257-266.

McIlwain H, Bachelard HS (1985) Biochemistry and the central nervous system, Vol 5, p 54. New York: Churchill Livingstone

Melzer P, Van der Loos H, Dörfl J, Welker E, Robert P, Emery D, Berrini JC (1985) A magnetic device to stimulate selected whiskers of freely moving or restrained small rodents: its application in a deoxyglucose study. Brain Res 348:229-240.

Menon R, Hu X, Mitra P, Ogawa S, Ugurbil K (1994) Signal characteristics in functional MRI of the brain upon visual stimulation. Soc Neurosci Abstr 20:148.

Mita M, Hall PF (1982) Metabolism of round spermatids from rats: lactate as the preferred substrate. Biol Reprod 26:445-455.

Miyaoka M, Shinohara M, Batipps M, Pettigrew KD, Kennedy C, Sokoloff $L$ (1979) The relationship between the intensity of the stimulus and the metabolic response in the visual system of the rat. Acta Neurol Scand [Suppl] 60:16/014193/

Moncada S, Palmer RMJ, Higgs EA (1991) Nitric oxide: physiology, pathophysiology, and pharmacology. Pharmacol Rev 43:109.

Morrison JH, Grzanna R, Molliver M, Coyle JT (1978) The distribution and orientation of noradrenergic fibers in neocortex of the rat: an immunofluorescence study. J Comp Neurol 181:17-40.

Ogawa S, Lee TM, Kay AR, Tank DW (1990) Brain magnetic resonance imaging with contrast dependent on blood oxygenation. Proc Natl Acad Sci USA 87:9868-9872.

Ogawa S, Tank DW, Menon R, Ellermann JM, Kim SG, Merkle H, Ugurbil K (1992) Intrinsic signal changes accompanying sensory stimulation: functional brain mapping with magnetic resonance imaging. Proc Natl Acad Sci USA 89:5951-5955.

O'Kusky J, Colonnier M (1982) A laminar analysis of the number of neurons, glia and synapses in the visual cortex (area 17) of the adult macaque monkey. J Comp Neurol 210:278-290.

Pardridge WM, Oldendorf WH (1977) Transport of metabolic substrates through the blood-brain barrier. J Neurochem 28:5/ 014193/ 
Paul RJ, Hardin DC, Raeymaekers L, Wuytack F, Casteels R (1979) Vascular smooth muscle: aerobic glycolysis linked to sodium and potassium transport processes. Science 206:1414-1416.

Paul RJ, Hardin DC, Raeymaekers L, Wuytack F, Casteels R (1989) Preferential support of $\mathrm{Ca}^{2+}$ uptake in smooth muscle plasma membrane vesicles by an endogenous glycolytic cascade. FASEB J 3:2298-2301.

Pearce B (1993) Amino acid receptors. In: Astrocytes: pharmacology and function (Murphy S, ed), pp 47-66. San Diego: Academic.

Pellegri G, Magistretti PJ, Martin J-L (1994) Regulation of gene expression by VIP and glutamate in cultured cortical neurons. Soc Neurosci Abstr 20:732.

Pellerin L, Magistretti PJ (1994) Glutamate uptake into astrocytes stimulates acrobic glycolysis: a mechanism coupling neuronal activity to glucose utilization. Proc Natl Acad Sci USA 91:10625 10629.

Peters A, Palay SL, Webster H de F (1991) The fine structure of the nervous system: neurons and their supporting cells. Philadelphia: Saunders.

Phelps CH (1972) Barbiturate-induced glycogen accumulation in brain. An electron microscopic study. Brain Res 39:225-234.

Phelps ME, Huang SC, Hoffman EJ, Selin C, Sokoloff L, Kuhl DE (1979) Tomographic measurement of local cerebral glucose metabolic rate in humans with (F-18)2-fluoro-2-deoxy-D-glucose:validation of method. Ann Neurol 6:371-388.

Poitry-Yamate CL (1994) Biosynthesis, release and possible transfer of glucose-derived carbohydrate intermediates and amino acids from mammalian glial cells to photoreceptor-neurons. Ph.D. Thesis, Université de Genève.

Poitry-Yamate CL, Tsacopoulos M (1992) Glucose metabolism in freshly isolated Müller glial cells from a mammalian retina.J Comp Neurol 320:257-266.

Prichard J, Rothman D, Novotny E, Petroff O, Kuwabara T, Avison M, Howseman A, Hanstock C, Shulman R (1991) Lactate rise detected by 'H NMR in human visual cortex during physiologic stimulation. Med Sci 88:5829-5831.

Proverbio F, Hoffman JF (1977) Membrane compartmentalized ATP and its preferential use by the $\mathrm{Na}^{+}-\mathrm{K}^{+}$ATPase of human red cell ghosts. J Gen Physiol 69:605-632.

Quach TT, Rose C, Schwartz JC (1978) [ ${ }^{3} \mathrm{H}$ ] Glycogen hydrolysis in brain slices: responses to neurotransmitters and modulation of noradrenaline receptors. J Neurochem 30:1335-1341.

Quach TT, Duchemin AM, Rose C, Schwartz JC (1980) [ $\left.{ }^{3} \mathrm{H}\right]$ Glycogen hydrolysis elicited by histamine in mouse brain slices: selective

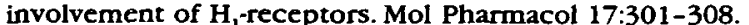

Quach TT, Rose C, Duchemin AM, Schwartz JC (1982) Glycogenolysis induced by serotonin in brain: identification of a new class of receptors. Nature 298:373-375.

Raffin CH, Rosenthal M, Busto R, Sick TJ (1992) Glycolysis, oxidative metabolism and brain potassium ion clearance. J Cereb Blood Flow Metab 12:34-42.

Raichle ME (1979) Quantitative in vivo autoradiography with positron emission tomography. Brain Res Rev 1:47-68.

Raichle ME (1994) Visualizing the mind. Sci Am 270:36-42

Raichle ME, Martin WRW, Herscovitch P, Mintun MA, Markham J (1983) Brain blood flow measured with intravenous $\mathrm{H}_{2}{ }^{15} \mathrm{O}$. II. Implementation and validation. J Nucl Med 24:790-798.

Reivich M, Alavi A (1983) Positron emission tomographic studies of local cerebral glucose metabolism in humans in physiological and pathophysiological conditions. Adv Metab Dis 10:135-176.

Reivich M, Kuhl D, Wolf A, Greenberg J, Phelps M, Ido T, Cassella V (1979) The ${ }^{18} \mathrm{~F}$-fluoro-deoxyglucose method for the measurement of local cerebral glucose utilization in man. Circ Res 44:127-137.

Roland P (1993) Brain activation, p 72. New York: Wiley-Liss.

Roy CS, Sherrington CS (1890) On the regulation of the blood supply of the brain. J Physiol (Lond) 11:85-108.

Sala L (1891) Zur feineren Anatomie des grossen Seepferdefusses. Zeitschr Wissenschaftl Zool Bd L11, Heft 1:18-45.

Sappey-Marinier D, Calabrese G, Fein G, Hugg JW, Biggins C, Weiner MW (1992) Effect of photic stimulation on human visual cortex lactate and phosphates using ${ }^{1} \mathrm{H}$ and ${ }^{31} \mathrm{P}$ magnetic resonance spectroscopy.J Cereb Blood Flow Metab 12:584-592.

Schasfoort EMC, DeBruin LA, Korf J (1988) Mild stress stimulates rat hippocampal glucose utilization transiently via NMDA receptors, as assessed by lactography. Brain Res 475:58-63.
Schurr A, West CA, Rigor BM (1988) Lactate-supported synaptic function in the rat hippocampal slice preparation. Science 240:13261328.

Selak I, Skaper S, Varon S (1985) Pyruvate participation in the low molecular weight trophic activity for CNS neurons in glia-conditioned medium. J Neurosci 5:23-28.

Shank RP, Campbell GLM (1984) Alpha-ketoglutarate and malate up take and metabolism by synaptosomes: further evidence for an astrocyte-to-neuron metabolic shuttle. J Neurochem 42:11531161.

Shank RP, Leo GC, Zielke HR (1993) Cerebral metabolic compartmentation as revealed by nuclear magnetic resonance analysis of D- $\left[1{ }^{13} \mathrm{C}\right]$ glucose metabolism. J Neurochem 61:315-323.

Sharp FR, Kauer JS, Shepherd GM (1975) Local sites of activity-related glucose metabolism in rat olfactory bulb during olfactory stimulation. Brain Res 98:596-600.

Shimizu N, Hamuro Y (1958) Deposition of glycogen and changes in some enzymes in brain wounds. Nature 181:781-782.

Siesjö BK (1978) Brain energy metabolism. Chichester: Wiley.

Sokoloff $L(1960)$ The metabolism of the central nervous system in vivo. In: Handbook of physiology-neurophysiology (Field J, Magoun HW, Hall VE, eds), pP 1843-1864. Washington, DC: American Physiological Society.

Sokoloff $\mathrm{L}$ (1981) Localization of functional activity in the central nervous system by measurement of glucose utilization with radioactive deoxyglucose. J Cereb Blood Flow Metab 1:7-36.

Sokoloff L. (1989) Basic neurochemistry: molecular, cellular, and medical aspects. New York: Raven

Sokoloff L (1991) Relationship between functional activity and energy metabolism in the nervous system: whether, where and why? In: Brain work and mental activity (Lassen NA, Ingvar DH, Raichle ME, Friberg L, eds), pp 52-64. Copenhagen: Munksgaard.

Sokoloff L, Reivich M, Kennedy C, Des Rosiers MH, Patlak CS, Pettigrew KD, Sakurada O, Shinohara M (1977) The [ $\left.{ }^{14} \mathrm{C}\right]$ deoxyglucose method for the measurement of local cerebral glucose utilization: theory, procedure, and normal values in the conscious and anesthetized albino rat. J Neurochem 28:897-916.

Sonnewald U, Westergaard N, Krane J, Unsgard G, Petersen SB, Schousboe A (1991) First direct demonstration of preferential release of citrate from astrocytes using [ $\left.{ }^{13} \mathrm{C}\right] \mathrm{NMR}$ spectroscopy of cultured neurons and astrocytes. Neurosci Lett 128:235-239.

Sorg O, Magistretti PJ (1991) Characterization of the glycogenolysis elicited by vasoactive intestinal peptide, noradrenaline and adenosine in primary cultures of mouse cerebral cortical astrocytes. Brain Res 563:227-233.

Sorg O, Kiraly M, Magistretti PJ (1993) Modulation of lactate release from primary astrocyte cultures. Soc Neurosci Abstr 19:60.

Stella N, Pellerin L, Magistretti PJ (1995) Modulation of the glutamateevoked release of arachidonic acid from mouse cortical neurons: involvement of a pH-sensitive membrane phospholipase A2. J Neurosci 15:3307-3317.

Stryer L (1988) Biochemistry, p 156. New York: Freeman.

Swanson RA (1992) Astrocyte glutamate uptake during chemical hypoxia in vitro. Neurosci lett 147:143-146.

Swanson RA, Yu ACH, Sharp FR, Chan PH (1989) Regulation of glycogen content in primary astrocyte culture: effect of glucose analogues, phenobarbital, and methionine sulfoximine.J Neurochem 52:1359-1365

Swanson RA, Morton MM, Sagar SM, Sharp FR (1992) Sensory stimulation induces local cerebral glycogenolysis: demonstration by autoradiography. Neuroscience 51:451-461.

Takahashi S, Driscoll BF, Law MJ, Sokoloff L (1995) Role of sodium and potassium ions in regulation of glucose metabolism in cultured astroglia. Proc Natl Acad Sci USA 92:4616-4620.

Teller DN, Banay-Schwartz M, Deguzman T, Lajtha A (1977) Energetics of amino acid transport into brain slices: effects of glucose depletion and substitution of Krebs' cycle intermediates. Brain Res 131:321-334

Tholey G, Roth-Schechter BF, Mandel P (1981) Activity and isoenzyme pattern of lactate dehydrogenase in neurons and astrobiasts cultured from brains of chick embryos. J Neurochem 36:77-81.

Tower DB, Young OM (1973) The activities of butyrylcholinesterase and carbonic anhydrase, the rate of anaerobic glycolysis, and the question of a constant density of glial cells in cerebral cortices of 
various mammalian species from mouse to whale. J Neurochem 20:269-278.

Tsacopoulos M, Veuthey A-L (1993) The nutritive function of glia in the crystal-ike nervous tissue: the retina of the honeybee drone. Dev Neurosci 15:336-342.

Tsacopoulos M, Evĉquoz-Mercier V, Perrottet P, Buchner E (1988) Honeybee retinal glial cells transform glucose and supply the neurons with metabolic substrates. Proc Natl Acad Sci USA 85:87278731.

Tsacopoulos M, Veuthey A-L, Saravelos SG, Perrottet P, Tsoupras G (1994) Glial cells transform glucose to alanine, which fuels the neurons in the honeybee retina. J Neurosci 14:1339-1351.

Ueki M, Linn F, Hossmann KA (1988) Functional activation of cerebral blood flow and metabolism before and after global ischemia of rat brain. J Cereb Blood Flow Metab 8:486-494.

Van Assendelft OW (1970) Spectrophotometry of haemoglobin derivatives, $p$ 65. Assen: Royal Vangorcum.

Vanderkooi JM, Wright WW, Erecinska M (1994) Nitric oxide diffusion coefficients in solutions, proteins and membranes determined by phosphorescence. Biochim Biophys Acta 1207:249254.

Walz W, Muckerji S (1988) Lactate release from cultured astrocytes and neurons: a comparison. Glia 1:366-370.

Watanabe $H$, Passonneau JV (1974) The effect of trauma on cerebral glycogen and related metabolites and enzymes. Brain Res 66:147159.

Wolf NK, Sharp FR, Davidson TM, Ryan AF (1983) Cochlear and middle ear effects on metabolism in the central auditory pathway during silence: a 2-deoxyglucose study. Brain Res 274:119-127.

Wolfe LS, Klatzo I, Miquel J. Tobias C, Haymaker W (1962) Effect of afpha-particle irradiation on brain glycogen in the rat. J Neurochem 9:213-218.

Yarowsky PJ, Boyne AF, Wierwille R, Brookes N (1986) Effect of mo nensin on deoxyglucose uptake in cultured astrocytes: energy metabolism is coupled to sodium entry. J Neurosci 6:859-866.

Yu N, Martin JL, Stella N, Magistretti PJ (1993) Arachidonic acid stimulates glucose uptake in cerebral cortical astrocytes. Proc Natl Acad Sci USA 90:4042-4046.

Zeki S, Watson JDG, Lueck CJ, Friston KJ, Kennard C, Frackowiak RSJ (1991) A direct demonstration of functional specialization in human visual cortex. J Neurosci 11:641-649. 